\title{
DESAIN SEPATU LAPANGAN PASUKAN INFANTERI TNI AD
}

\author{
Alan David Prayogi ${ }^{1}$ \\ Sekolah Tinggi Teknik Surabaya, \\ Surabayalalan@stts.edu
}

\begin{abstract}
Abstrak
Bagi infanteri, kaki adalah anggota tubuh yang sangat penting saat berada di medan pertempuran. Jika terjadi cidera pada kaki, hampir dapat dipastikan seorang tentara akan kalah pada pertempuran dikarnakan tidak adanya lagi mobilitas yang dimiliki oleh tentara tersebut. Maka dari itu diperlukan sepatu yang dapat menjaga kondisi kaki agar tetap nyaman dan aman saat bertugas, dan tentunya juga dilengkapi dengan fungsi yang optimal dalam mendukung aktivitas infanteri. Akan tetapi kenyataannya, sepatu lapangan yang ada saat ini masih belum sempurna dalam memenuhi kebutuhan infanteri. Maka dari itu fokus dari riset ini adalah menciptakan desain sepatu lapangan yang ergonomis dan fungsional dalam beradaptasi dengan medan dan kondisi alam di Indonesia. Produk akhir yang dihasilkan dari perancangan ini adalah sepatu lapangan yang memiliki sistem modular yang dapat disesuaikan dengan kondisi medan yang dilalui. Hasil uji coba terhadap final produk pun berhasil menunjukkan bahwa sepatu yang baru berhasil menunjukkan performa yang lebih baik, yang telah dibuktikan dengan metode dr. Woldemar Gerschler. Adapun kendala yang dilalui selama penelitian adalah sulitnya melakukan research \& development yang lebih dalam terhadap material karna singkatnya waktu, terlebih karna adanya pandemic covid-19.
\end{abstract}

Kata kunci: Sepatu, Sepatu Lapangan, Pasukan Infanteri

\begin{abstract}
For infantry, legs are very important limbs when on the battlefield. If there is an injury to the leg, it is almost certain that a soldier will lose the battle because there is no more mobility that the soldier has. Therefore, shoes are needed that can keep the feet comfortable and safe while on duty, and of course also equipped with optimal functions in supporting infantry activities. However, in reality, the current field boots are still imperfect in meeting infantry needs. Therefore the focus of this research is to create an ergonomic and functional field shoe design in adapting to the terrain and natural conditions in Indonesia. The final product produced from this design is a field shoe that has a
\end{abstract}


modular system which can be adapted to the terrain conditions being traversed. The test results on the final product also showed that the new shoes managed to show better performance, which has been proven by the method of dr. Woldem ar Gerschler. The obstacles that were passed during the research were the difficulty of doing deeper research \& development on the material because of the short time, especially because of the Covid-19 pandemic.

Keywords-Shoes, Field Shoes, Infantry

\section{PENDAHULUAN}

Sepatu Pakaian Dinas Lapangan atau biasa dikenal dengan sepatu PDL adalah sepatu yang dibuat untuk digunakan saat melaksanakan tugas pada area yang banyak berhubungan dengan kegiatan lapangan dan sejenisnya yang biasanya digunakan oleh Tentara Nasional Indonesia (TNI), dan Kepolisian Negara Republik Indonesia (Polri). Jadi dapat dikatakan bahwa sepatu ini akan sangat sering atau bahkan hampir selalu digunakan oleh TNI dalam aktivitas lapangan dan tentunya merupakan equipment yang sangat penting untuk menunjang aktivitas tersebut terlebih pada aktivitas lapangan yang pasukan infanteri TNI-AD. Infanteri sendiri merupakan pasukan tempur darat utama yaitu pasukan pejalan kaki yang dilengkapi persenjataan ringan, dilatih dan disiapkan untuk melaksanakan pertempuran jarak dekat. Infanteri berasal dari kata infant yang berarti kaki, biasanya untuk menggambarkan para tentara muda yang berjalan kaki di sekeliling para kesatria yang menunggang kuda atau kereta. Oleh karena itu seorang infanteri harus memiliki kemampuan bertempur tangan kosong, menembak, dan bertempur dalam segala medan dan cuaca. Bagi pasukan infanteri TNI-AD, medan dan cuaca di Indonesia haruslah dapat dikuasai dengan baik. Seperti karakteristik medan yang bertanah, lumpur, bebatuan, pasir, sungai dan juga dua musim di Indonesia yakni musim hujan dan kemarau yang membuat peran sepatu lapangan sangat penting untuk menghadapi medan-medan tersebut.

Karakteristiknya pun juga beragam dan juga memiliki tingkat kesulitan yang berbeda-beda. Berikut klasifikasi yang telah penulis buat melalui deep interview mengenai tingkat kesulitan pada trek medan dan cuaca di Indonesia : 
Tabel I. Klasifikasi tingkat kesulitan medan dan cuaca di Indonesia

\begin{tabular}{|c|c|}
\hline Tingkat Kesulitan & is Medan dan Cuaca \\
\hline Ekstrem A & $\begin{array}{c}\text { Sungai, lumpur, tebing- } \\
\text { tebing }\end{array}$ \\
\hline Ekstrem B & $\begin{array}{c}\text { Bebatuan, medan } \\
\text { berpasir }\end{array}$ \\
\hline Ekstrem C & Hutan, Panas, Hujan \\
\hline
\end{tabular}

Sumber: Dokumen Pribadi

Tabel diatas menjelaskan bahwa Ekstrem A adalah yang paling sulit untuk dilalui, diikuti dengan Ekstrem B dan Ekstrem C. Karakteristiknya pun berbeda-beda dan memerlukan sepatu lapangan yang baik dan dapat dengan optimal digunakan di lapangan.

Selain itu, sepatu lapangan pasukan infanteri TNI-AD biasanya di desain cukup tinggi dengan tujuan untuk melindungi bagian kaki saat bertugas. Hal tersebut membuat sepatu ini memiliki berat $1,5 \mathrm{~kg}$ yang tentunya cukup berat dan kurang nyaman saat digunakan dalam durasi yang lama. Juga banyak ditemukan keluhan bahwa jika sepatu ini digunakan terlalu lama maka kaki akan mudah lecet dan terasa perih. Selain itu dari segi efisiensi sepatu ini juga masih kurang maksimal, karena tidak semua medan dapat diatasi secara baik dengan sepatu ini, seperti misalnya, saat melewati medan yang berair atau basah, pasukan infanteri harus mengganti sepatu lapangan mereka ke sepatu boots dikarnakan sepatu mereka yang tidak dapat kering dengan cepat, tentunya hal itu kurang efisien karna membuat mereka harus membawa dua sepatu secara bersamaan. Akan lebih efisien jika hanya membawa satu sepatu yang sudah memenuhi kedua kebutuhan tersebut untuk memaksimalkan storage yang terbatas dan juga pemanfaatan waktu yang lebih maksimal.

Melihat semua fakta-fakta diatas, dapat disimpulkan bahwa sepatu lapangan TNI harus diperbaiki untuk dapat memenuhi beberapa fungsi secara lebih optimal dan juga harus dilakukan pengoptimalan kembali dalam segi ergonominya. Untuk mencapai hal tersebut diperlukan parameter ergonomi atau tidaknya suatu sepatu lapangan. 


\section{METODE PENELITIAN}

a. Tahap Pengambilan Data

Metode pengambilan data diperoleh dengan pengumpulan data primer melalui kuisoner dan juga deep interview dengan pasukan infanteri TNI-AD di kompleks Kodam V Brawijaya Surabaya. Selain itu juga dilakukan metode observasi/pengamatan yang dilakukan peneliti pada pasukan infanteri TNI-AD. Sedangkan data sekunder diperoleh dari literatur seputar sepatu lapangan, ergonomi sepatu, dan buku informasi seputar infanteri.

b. Rencana Kegiatan

Tahapan studi dan analisa adalah meliputi bagiamana merancang sepatu lapangan untuk pasukan infanteri TNI-AD yang dapat beradaptasi dengan kondisi medan Indonesia. Berikut tahapan rencana kegiatan yang telah dilakukan :

1. Survey ke komplek Kodam V Brawijaya Surabaya untuk mendapatkan data berupa kebutuhan pasukan infanteri dan kekurangan existing product melalui kuisoner dan deep interview.

2. Survey beberapa produsen sepatu lapangan di UD.Zacyndo Surabaya, dan SP Collection Sidoarjo untuk mendapatkan standarisasi produk, dan existing product.

3. Review dan evaluasi terhadap existing product.

4. Melakukan beberapa analisa yakni analisa existing product, analisa medan dan kondisi Indonesia, analisa tren, analisa kebutuhan, analisa material, analisa ergonomi, dan analisa komponen tambahan.

5. Membuat Objective Tree.

6. Melakukan brainstorming untuk mendapatkan konsep dan inovasi.

7. Melakukan initial sketches, developtment sketches, hingga

alternatives sketches.

8. Membuat gambar 3D untuk mendapatkan gambaran bentuk final 
prototype sepatu.

9. Pembuatan prototype akhir. Uji Fisiologi dan wear test untuk memastikan bahwa produk yang dirancang lebih baik dibandingkan existing product

\section{KONSEP DAN ANALISA}

a. Konsep Perancangan

Konsep yang telah dibuat adalah berdasarkan semua analisa yang telah dilakukan. Dari analisa yang telah dibuat, berikut konsep-konsep perancangan yang diangkat pada tugas akhir ini :

1. Konsep desain yang diambil oleh sepatu ini adalah Badak Bercula Satu, dikarnakan hewan langka ini merupakan hewan representatif Indonesia. Selain itu hewan ini juga mewakili beberapa ciri dari pasukan infanteri, seperti badannya yang kekar, larinya yang cepat, powerful, serta memiliki senjata yakni culanya. Maka dari itu beberapa aspek tersebut di tuangkan dalam sepatu ini di dukung dengan analisa yang mendalam.

2. Konsep berikutnya adalah sepatu ini memiliki sistem modular sehingga beberapa fiturnya dapat disesuaikan dengan kebutuhan dengan sistem plug-in.

3. Konsep terakhir adalah sepatu ini harus sesuai dengan kondisi medan dan iklim di Indonesia.

b. Analisa

Berikut adalah beberapa analisa yang telah dilakukan penulis dalam penelitan ini: 
1. Analisa Existing Product

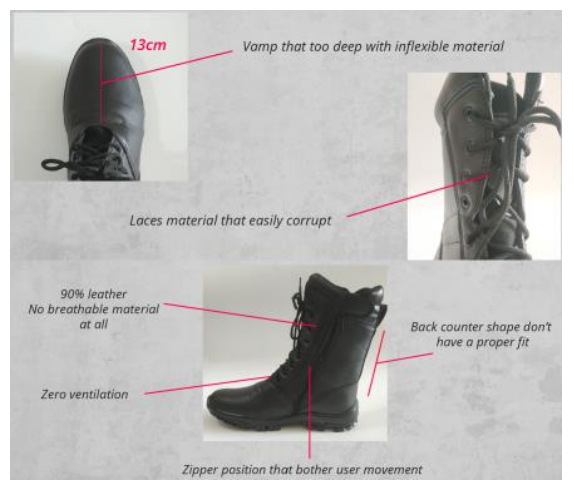

Gambar 1. Analisa Existing Product

Pada perancangan ini berdasarkan observasi dan hasil kuisoner yang di dapat, existing product yang digunakan saat ini masih memiliki banyak kekurangan, seperti masalah sepatu yang tidak memiliki ventilasi hingga menjadi panas, sepatu yang terlalu berat, kecepatan kering yang lama jika basah, hingga bentuknya yang tidak fit dan kurang menarik. Maka dari itu dilakukan kajian ulang untuk merancang sepatu lapangan yang terbaru.

2. Analisa Medan dan Iklim di Indonesia

Medan di Indonesia dapat dikategorikan sebagai medan yang cukup ekstrem, mengingat dengan trek yang cukup beragam. Selain itu, Indonesia juga memiliki dua musim yakni musim kemarau dan musim hujan, yang membuat analisa ini sangat penting untuk dilakukan. Maka dari itu dari penelitian ini dapat ditentukan kriteria material yang diperlukan adalah material yang waterproof dan breathable. Selain itu juga dapat ditentuan bentuk desain dan juga fitur yang diperlukan. 
3. Analisa Tren

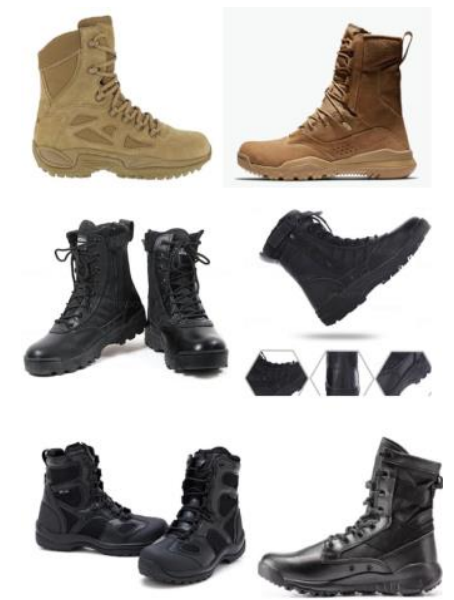

Gambar 2. Moodboard Tren

Analisa berikutnya dalah analisa tren dengan cara melakukan observasi pada tiap sepatu lapangan milik negara lain yang nantinya akan dilakukan penyesuaian kembali dengan kebutuhan pasukan infanteri TNI-AD. Hasilnya adalah tren bentuk sepatu yang ada saat ini adalah sepatu yang tidak gemuk/bulky melainkan cenderung ramping dan aerodinamis. Selain itu memiliki trent fullfill the task dengan menambahkan fitur-fitur yang diperlukan dan juga beberapa teknologi yang menjadi tren antara lain ultralight technology, Vibram technology, dll.

4. Analisa Kebutuhan

Dapat disimpulkan kebutuhan pasukan infanteri adalah sepatu yang aman, nyaman, dan fungsional. Setelah itu dilakukan Quality Function Deployment (QFD) untuk menentukan aspek-aspek yang harus diutamakan dalam memenuhi kebutuhan di atas yang hasilnya adalah pemilihan material adalah aspek terpenting yang harus diperhatikan, diikuti dengan dimensi dan ergonomi, bentuk desain sepatu, dan komponen tambahan.

\section{Analisa Material}


Pada perancangan ini berdasarkan referensi penelitian gesek material sol dan upper oleh Djalu Djatmiko dan Mohamad Arif yang lalu dipastikan kembali dengan matriks peniliain. Penulis memilih material Thermo Plastic Rubber sebagai material sol dan Pull Up Leather sebagai material upper. Kedua material itu dinilai yang paling kuat, nyaman, dan juga murah untuk digunakan sebagai material sepatu lapangan yang memerlukan durability dan flexibility yang baik. Selain itu material lainnya adalah GORE-TEX sebagai material yang waterproof dan breathable.

6. Analisa Ergonomi

Analisa ergonomi ini meliputi analisa gerakan kaki, tumpuan kaki, dan juga analisa antropometri kaki. Hal ini dimaksudkan agar hasil perancangan dapat sesuai dan juga nyaman dengan karakteristik kaki pasukan infanteri.

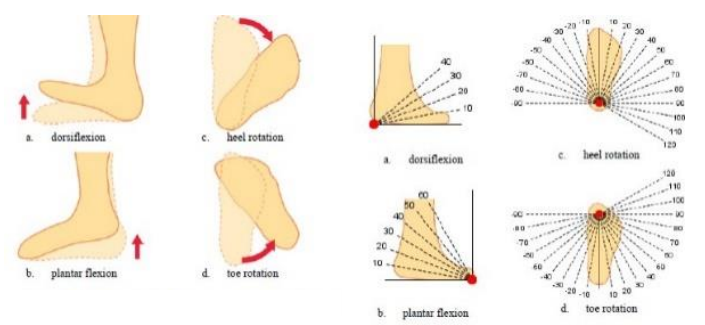

Gambar 3. Gerakan Kaki

Gambar diatas adalah illustrasi dari gerakan kaki pada manusia yang perlu diperhatikan sebelum merancang sebuah sepatu lapangan, berikut adalah penjelasannya ;

a. Dorsiflexion : melibatkan rotasi pergelangan kaki sehingga sudut antara tulang kering dan kaki menurun.

b. Plantar Flexion : melibatkan rotasi pergelangan kaki sehingga sudut di atas meningkat.

c. Heel Rotation : melibatkan rotasi internal dan eksternal kaki dan tungkai sambil memutar (pivoting) rotasi di ujung kaki. 
Gerakan-gerakan diatas membuat peletakkan material sepatu haruslah tepat agar tidak menghalangi gerakan-gerakan tersebut. Juga diperlukan support tambahan dari grip outsole agar kaki dapat berotasi dan melakukan pivoting dengan nyaman dan baik.

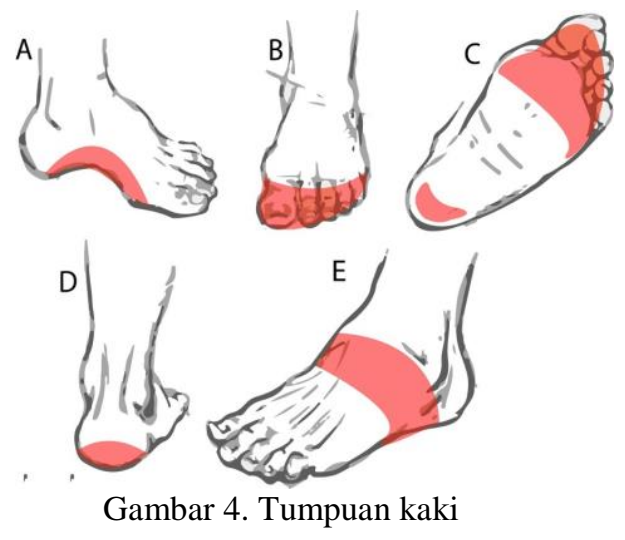

Gambar diatas adalah analisa gerak kaki dan bagian pada kaki yang akan terkena dampak saat beraktifitas. Berikut penjelasannya secara rinci ;

a. Area tersebut adalah area tulang plantar yang harus dilindungi, dikarnakan area tersebut pada umumnya akan mendapatkan banyak tekanan saat beraktifitas. Seperti lompatan, mendarat, dan sebagainya. Area ini adalah arch protect area.

b. Area ini adalah area jari-jari kaki yang harus dilindungi (Toe protect area). Biasanya area ini harus mendapat perlindungan dari toe cap dan toe box.

c. Dua area ini adalah area yang akan mendapatkan tekanan setelah melompat dan juga area yang paling sering menerima beban tumpuan. Biasanya area tumit akan diberikan ekstra cushion untuk mensupport dalam aktivitasnya.

d. Area ini yang dimaksud pada penjelasannya sebelumnya, peletakkan cushion sangat diperlukan disini.

Area ini adalah flex area yakni area pada bagian kaki yang sangat fleksibel. Area ini disarankan untuk tidak dibatasi dengan material yang kurang fleksibel agar tidak mengganggu pergerakan kaki. 
Tabel II. Acuan ukuran sepatu

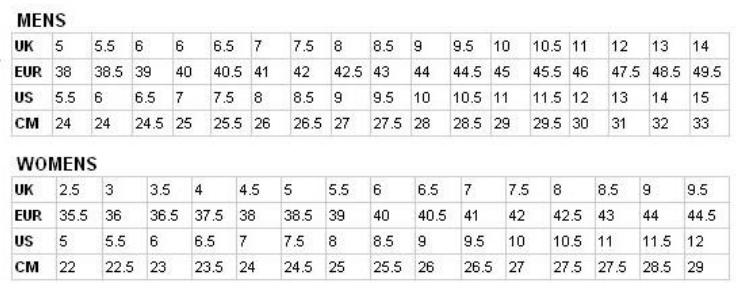

Pada proses perancangan ini juga penting untuk mengetahui standar ukuran sepatu yang tentunya banyak digunakan sebagai size sepatu seluruh dunia khususnya Indonesia. Mengetahui ukuran sepatu yang banyak dijual di Indonesia dan menjadi salah satu yang paling digemari juga dapat menjadi acuan untuk mengukur ukuran sepatu yang sesuai untuk orang Indonesia.

\section{Analisa Bentuk}

Analisa berikutnya adalah analisa bentuk sepatu, analisa ini dibagi menjadi dua yakni analisa upper dan outsole. Berikut analisa yang telah penulisa lakukan :

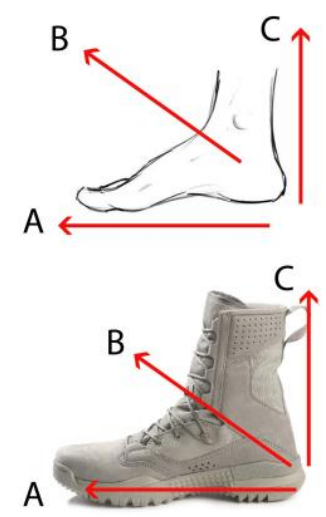

Gambar 5. Analisa Bentuk Upper

Pada gambar diatas dapat dilihat arah jahitan dan bentuk part pada upper yang sesuai dengan arah kaki. Arah jahitan dan bentuk part (A) menuju ke arah depan sesuai dengan arah kaki saat bergerak, arah dan part (B) sedikit diagonal dikarnakan kaki akan menekuk di area tersebut saat berlari, sedangkan arah dan part (C) boleh 
menggunakan arah horizontal maupun vertikal dikarnakan area kaki tersebut cenderung tidak melakukan perubahan gerakan.

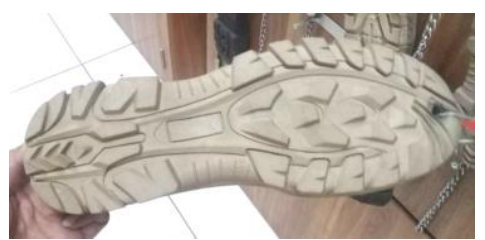

Gambar 6. Analisa Outsole

Bentuk outsole yang baik dan efektif untuk sepatu lapangan ini adalah outsole yang cukup menonjol/timbul keluar. Hal ini dikarnkan bentuk tersebut akan lebih maksimal saat bermanuver di medan berat dan memiliki kekuatan grip yang lebih baik. Selain itu jarak tonjolan yang satu dan yang lain diharapkan sedikit berjauhan dan tidak berdempet, agar disaat tanah basah menempel pada sepatu akan lebih mudah untuk melepaskan tanah tersebut.

8. Analisa Komponen Tambahan

Melihat product existing yang digunakan oleh pasukan infanteri saat ini, perlu ditambahkan komponen- komponen lain guna memberikan fitur yang lebih maksimal untuk sepatu yang akan dikerjakan seperti sabuk, ventilasi, memory foam insole, dan juga senjata.

\section{HASIL}

Berikut adalah desain final yang telah dibuat setelah melalui serangkaian proses perancangan : 


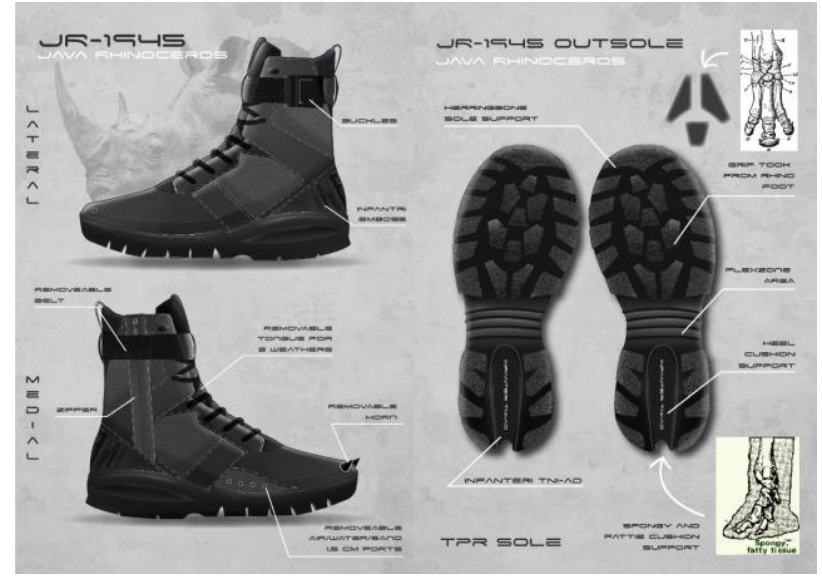

Gambar 7. Gambar Desain Final

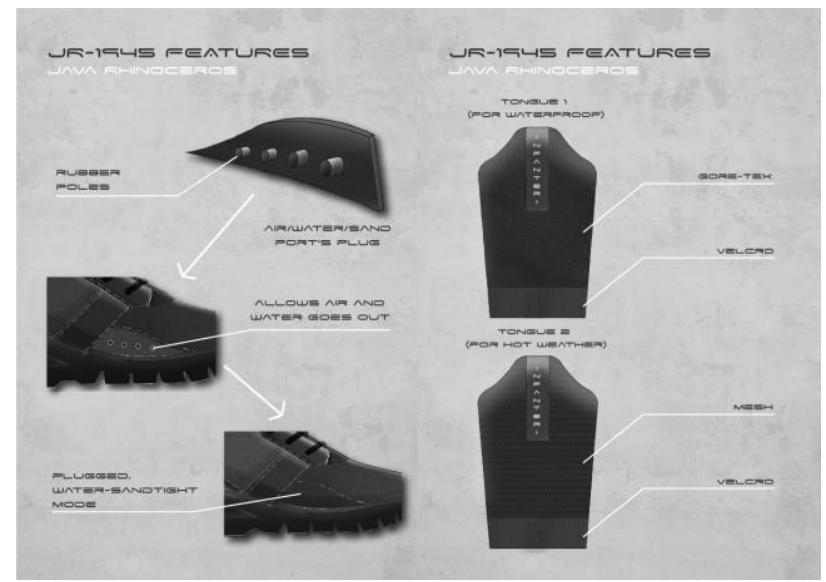

Gambar 8. Fitur Desain Final

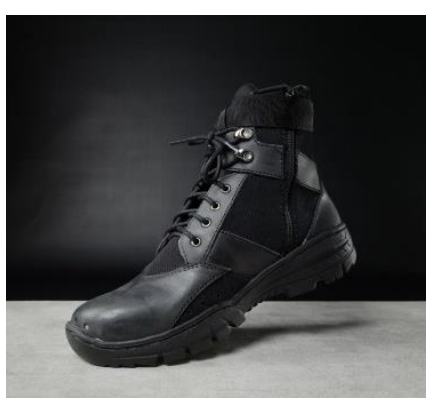

Gambar 9. Hasil Prototype 


\section{PENUTUP}

A. Kesimpulan

Setelah melalui segala proses dalam perancangan sepatu ini, berikut hasil kesimpulan dari rumusan masalah yang telah dibuat :

1. Untuk membuat desain sepatu lapangan pasukan infanteri TNI-AD yang dapat lebih mendukung aktivitas mereka dibandingkan sepatu yang digunakan saat ini oleh pasukan infanteri banyak hal-hal yang perlu diperhatikan. Hal utama yang harus diperhatikan adalah pemilihan material, material yang digunakan tidak hanya harus durable, tetapi juga harus memiliki mobilitas dan fleksibilitas yang baik. Selain itu material yang sangat disarankan adalah material waterproof breathable layaknya gore tex. Tetapi semua hal tersebut harus didukung dengan pengetahuan mengenai gerak kaki manusia sehingga nantinya peletakan material dapat sesuai dengan kebutuhan gerak kaki manusia.

2. Indonesia memiliki 2 musim, yakni musim hujan dan kemarau. Melihat hal tersebut sepatu lapangan harus dapat beradaptasi dalam hujan maupun cuaca panas. Maka dari itu solusinya adalah dengan membuat tongue sepatu menjadi 2 dengan system modular, yakni tongue untuk cuaca panas, dan tongue waterproof. Selain itu sepatu harus memiliki banyak ventilasi yang tetap anti air dan pasir. Maka dari itu system plug pada port ventilasi merupakan solusi.

3. Lalu untuk lebih jelasnya, berikut kriteria standar sepatu lapangan infanteri TNI-AD yang telah penulis rumuskan :

- Mudah kering disaat basah

- Ringan dan dilengkapi dengan material yang breathable, waterproof, dan juga durable (disarankan material leather dan gore- tex).

- Dapat beradaptasi dengan kondisi dan lingkungan Indonesia

- Memiliki ventilasi yang cukup 
B. Saran

Perancangan sepatu lapangan ini masih jauh dari sempurna, mengingat waktu yang sangat singkat dan juga adanya pandemi covid-19 yang tentunya menghambat penulis untuk melakukan lebih banyak penelitian, maka masih banyak aspek yang belum dapat dikaji secara lebih maksimal. Berikut beberapa saran dari penulis bagi peneliti berikutnya ;

1. Perlu tim research \& development dari pabrik sepatu yang lebih kompoten untuk menghasilkan desain sepatu terutama part outsole dapat lebih menarik. Waktu yang singkat dan cukup sulitnya menemukan pabrik yang mau mendevelop outsole baru membuat desain outsole menjadi kurang 'liar'.

2. Bagian ports ventilasi dan plugs systemnya dapat diganti dengan TPR sehingga lebih mudah pemasangannya dan lebih kedap air dan pasir.

3. Dapat dilakukan analisis tekstur tanah yang ada di Indonesia untuk dapat lebih meningkatkan lagi performa sepatu.

\section{DATAR PUSTAKA}

Army Study Guide. 2017. Move Under Direct Fire. Diakses 20 Mei 2020 dari https://www.armystudyguide.com

David, Alan. 2019. Desain rompi serbu ergonomis untuk prajurit TNI- AD dengan konsep modular (Tesis Magister). Institut Teknologi Sepuluh Nopember Surabaya.

Djatmiko, Djalu. 2013. Pengkajian Kualitas Material dan Konstruksi Upper pada Proses Perancangan Sepatu Olahraga Ekstrim Skateboard. Bandung: Desain Institut Teknologi Nasional.

Tribowo, Sando. 2014. Desain Serial Sepatu Gunung dengan Konsep Waterproof Breathable (Tugas Akhir) Institut Teknologi Sepuluh Nopember Surabaya.

Prasetya, Devindo. 2016. Desain Serial Sepatu Basket Streetball Bercirikan Indonesia. Surabaya: Desain Produk Industri, Teknik Sipil dan Perencanaan 
Institut Teknologi Sepuluh Nopember.

Republik Indonesia.2004. Undang Undang Nomor 34. Tugas, Fungsi, dan Peran TNI. Jakarta. 